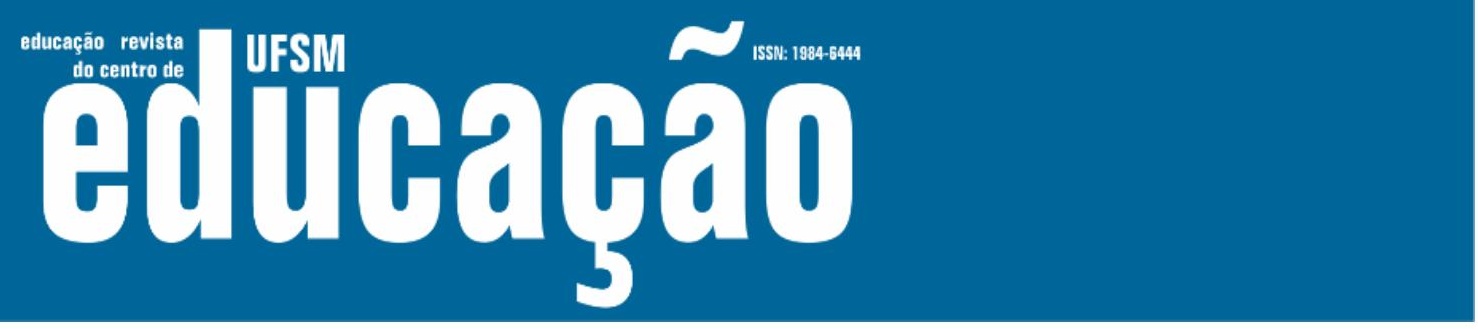

ISSN: 1984-6444 | http://dx.doi.org/10.5902/1984644442037

\title{
Efeitos dos modelos econômicos nas políticas de distribuição de bens linguísticos no Brasil
}

\author{
Effects of economic models on linguistic goods distribution policies in \\ Brazil
}

\author{
Emerson de Pietri \\ Professor associado da Universidade de São Paulo, São Paulo, Brasil. \\ pietri@usp.br - http://orcid.org/0000-0001-5060-9891
}

Recebido em 28 de janeiro de 2020

Aprovado em 09 de abril de 2021

Publicado em 28 de maio de 2021

\section{RESUMO}

Com o objetivo de contribuir para a compreensão dos processos de distribuição de bens linguísticos na sociedade brasileira, são observadas, neste trabalho, as mudanças que se operaram nas bases econômicas de produção capitalista, a partir da década de 1970, e os projetos políticos, sociais e educacionais definidos para o país em diferentes conjunturas históricas desde então constituídas. A não consideração mais detalhada das mudanças nas bases econômicas e de seus efeitos para a manutenção ou amplificação da desigualdade social dificulta a observação mais atenta do funcionamento, nessa ordem, dos projetos oficiais para o ensino de língua portuguesa no Brasil. Nesse sentido, são evidenciadas, com base em conceitos da análise do discurso de linha francesa, as tensões resultantes da concorrência entre modelos político-econômicos implantados no país, nas três últimas décadas do século XX e nas décadas iniciais do século XXI, e suas relações com a constituição de concepções concorrentes de língua e de sujeito da aprendizagem, estabelecidas, no período observado, em políticas públicas de educação e materializadas em documentos de parametrização curricular. Os resultados apontam para a necessidade de questionar os efeitos da implantação de um currículo nacional comum para o ensino de língua portuguesa quando são mantidas as condições desiguais de escolarização, em um contexto de destruição de políticas sociais e de fortalecimento das bases concorrenciais na ordem econômica do país, expandidas agora para as classes mais pobres.

Palavras-chave: Ensino de Português; Desigualdade econômica; Currículo. 


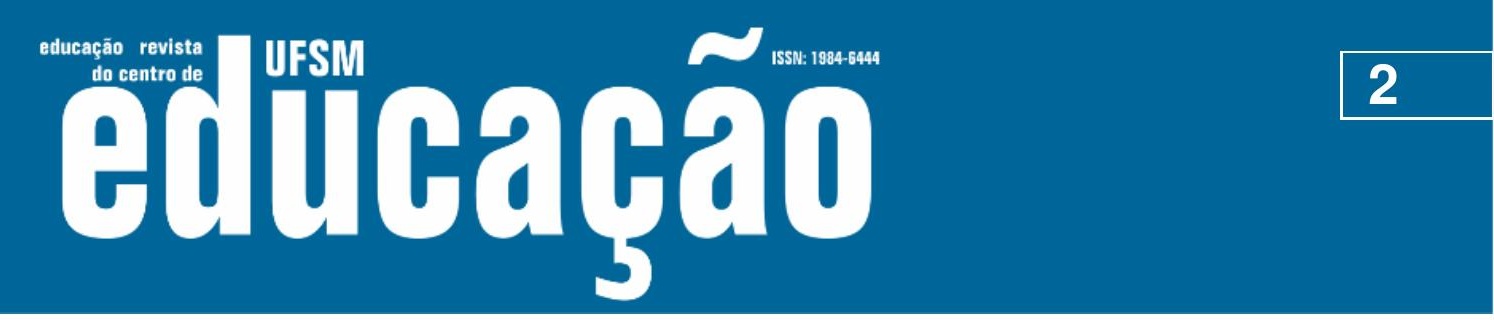

ISSN: 1984-6444 | http://dx.doi.org/10.5902/1984644442037

\begin{abstract}
In this work, changes in the economic bases of capitalist production since the 1970s are observed, with the aim of contributing to the understanding of the processes of distribution of linguistic goods in Brazilian society. The lack of more detailed analysis of changes in economic bases and their effects for the maintenance and expansion of social inequality makes it more difficult to observe more closely the functioning of official projects for the teaching of Portuguese in Brazil. Based on the concepts of the Discourse Analysis, the tensions resulting from the competition between political and economic models, implanted in the country in the last five decades, are evidenced in their relations with the constitution of competing conceptions of Portuguese teaching and learning established in public education policies and materialized in curricular parameterization documents. The results show that it is necessary to question the effects of implementing a common national curriculum for language teaching when unequal schooling conditions are maintained, in a context of destruction of social policies and the subjection of the poorest to the competitive economic order.
\end{abstract}

Keywords: Portuguese teaching; Economic inequality; Curriculum.

\title{
Introdução
}

Neste trabalho, são observados os efeitos dos modelos econômicos implantados em concorrência, no país, nas três últimas décadas do século XX e nas décadas iniciais dos anos 2000, para as políticas de distribuição linguística estabelecidas pelo Estado brasileiro. A observação de documentos de parametrização curricular para o ensino de língua portuguesa na escolarização pública, produzidos por instâncias oficiais responsáveis pela educação, possibilita conhecer as relações que se estabeleceram historicamente nas tensões produzidas entre modelos econômicos divergentes e diferentes projetos de distribuição de bens linguísticos no país.

As políticas de distribuição do ensino de língua portuguesa no Brasil respondem historicamente a projetos de poder que reconfiguram continuamente 0 Estado e seus limites em função do que se estabelece como sociedade brasileira em uma ou em outra base ideológica, com limites sociais diversos para a distribuição de bens econômicos e simbólicos (dentre eles, os linguísticos). Mantêm-se, assim, desde o período colonial, a proporção de um terço da população que é abarcada 


\section{HSW

ISSN: 1984-6444 | http://dx.doi.org/10.5902/1984644442037

pelos domínios do Estado e seus serviços, e os outros dois terços dessa população que são integrados nesses limites de modo supletivo e/ou intermitente, como será discutido mais adiante.

A desigualdade estrutural que constitui o Estado brasileiro sustenta um processo clivado para a distribuição linguística, que, como demonstra Lucchesi (2015), faz-se historicamente de modo a integrar em torno de $30 \%$ da população que pode apropriar-se do português brasileiro em seus usos valorizados socialmente, e interditar/excluir em torno de $70 \%$ dos que têm o acesso ao português brasileiro impossibilitado em diferentes níveis, de modo que possuem como língua corrente o português popular brasileiro com suas gradações em direção ao português brasileiro e sua norma legitimada e valorizada socialmente.

Os efeitos, para a educação, da clivagem social e econômica estruturante da sociedade brasileira são percebidos, mais evidentemente, a partir da década de 1970, quando chegam aos bancos escolares contingentes cada vez maiores de estudantes vindos das camadas populares, por um lado, e, por outro, quando se realiza a repartição mais bem definida entre sistemas privados e públicos de ensino (cf. FREITAS, 2004; OLIVEIRA, 2009; PERONI; CAETANO, 2015), reposicionados pelo modelo desenvolvimentista do regime militar.

Nessa ordem, os deslocamentos nos modos como se concebe a coisa pública, a partir da década de 1970 do século XX, com os processos de globalização da economia (SANTOS, 2000) e de financeirização do sistema capitalista (PAULANI, 2009), ora respondem a propostas de constituição do estado de bem estar social, ora respondem ao jogo de interesses que reconfigura a ordem social e econômica no neoliberalismo (FOUCAULT, 2008, p. 199).

São observados, neste artigo, os efeitos produzidos pela concorrência entre projetos políticos de base social e de base econômico-financeira para a redefinição dos limites do estado e das posições sociais no interior do sistema de classes, com os efeitos que essa concorrência produz nas bases legais em que se sustentam as relações sociais e trabalhistas (ANTUNES; POCHMANN, 2007), e, em consequência, nos processos de constituição de políticas públicas educacionais de distribuição de bens linguísticos. 


\section{Althaห̧ão}

ISSN: 1984-6444 | http://dx.doi.org/10.5902/1984644442037

Analiticamente, considera-se que a constituição histórica dos discursos sobre ensino de língua portuguesa no Brasil, nas décadas finais do século XX e iniciais do século XXI, realizou-se segundo um processo de concorrência interdiscursiva (MAINGUENEAU, 2005) entre discursos de caráter social, liberal e neoliberal, com as relações complexas que se estabeleceram entre esses discursos nesse processo.

Assumindo-se uma perspectiva discursiva para a produção e a análise dos dados, os documentos analisados serão considerados em função da proposta de Maingueneau (2005) de que os enunciados de um discurso constituem-se com base em regras semânticas específicas que definem seu pertencimento a esse dado discurso, regras que definem também enunciados que lhe são estranhos: concebido o sistema de restrições semânticas como um modelo de competência discursiva, considera-se que os enunciadores de um discurso dado apresentam o "domínio tácito de regras que permitem produzir e interpretar enunciados que resultam de sua própria formação discursiva e, correlativamente, permitem identificar como incompatíveis com ela os enunciados das formações discursivas antagonistas" (MAINGUENEAU, 2005, p. 23).

Considera-se, assim, como unidade de análise, não o discurso - entendido como "dispersão de textos cujo modo de inscrição histórica permite definir como um espaço de regularidades enunciativas" (MAINGUENEAU, 2005, p. 15) -, mas um espaço de trocas entre vários discursos convenientemente escolhidos, o que supõe, portanto, a precedência do interdiscurso sobre o discurso. Para Maingueneau (1997), a interdiscursividade pode ser observada no fato de que as polêmicas em que as formações discursivas estão envolvidas são a atualização de um processo de delimitação recíproca. Considerados dessa maneira, os discursos "nascem" de um trabalho sobre outros discursos, através de um processo contínuo fundamentado em um mecanismo de interincompreensão (MAINGUENEAU, 1997, p. 120).

A análise dos documentos de parametrização curricular para 0 ensino de língua portuguesa no Brasil, produzidos após a década de 70 do século $X X$, parece evidenciar um processo de aumento das tensões entre os discursos sobre ensino de 


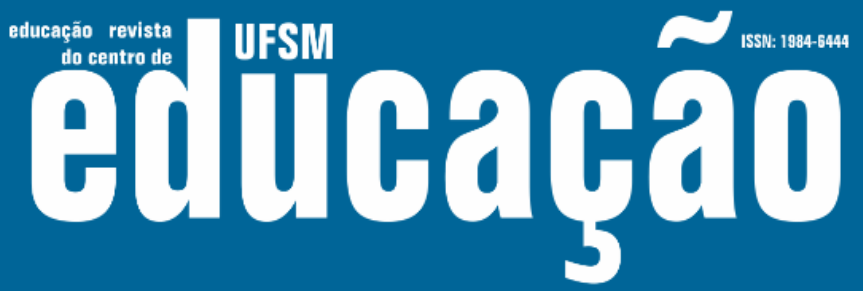

ISSN: 1984-6444 | http://dx.doi.org/10.5902/1984644442037

português produzidos no período observado, ainda que as relações interdiscursivas tenham sido por vezes representadas como de síntese e continuidade pelos discursos que se sucederam na posição dominante entre a década de 1970 e a segunda metade da década de 2010. Esse processo, como se procura mostrar neste trabalho, pode estar associado à concorrência e, por um período importante, à coocorrência de modelos econômicos conflitantes em seus projetos de conformação do Estado e da sociedade a interesses sociais e políticos em disputa.

A redefinição das relações interdiscursivas, sobre o ensino de português, desde o primeiro decênio dos anos 2000, evidencia esse aumento das tensões entre os discursos, com a contraposição de princípios de base social aos de base neoliberal, nas políticas educacionais estabelecidas no período de 2003 a 2013, e com a reação dos interesses neoliberais, na conjuntura formada a partir de 2014. Essa reação levou à ruptura da ordem institucional no ano de 2016, quando o discurso alçado à posição de agente se fundamenta em bases semânticas contrárias, opostas, inversas, àquelas de caráter sócio-histórico estabelecidas mais fortemente dos anos iniciais da década 80 a meados dos anos 1990.

\section{A construção do Estado brasileiro em seus limites econômicos e sociais}

Ao longo do século $X X$, às tensões entre forças liberais e patrimonialistas agrário-exportadoras ${ }^{1}$, sucederam-se disputas de interesses econômicos resultantes dos reposicionamentos geopolíticos do país na ordem internacional, mas, principalmente, os efeitos decorrentes das crises do capitalismo nas décadas finais do século XIX e iniciais do século XX, até 1929, e da II Grande Guerra. Segundo Pochmann (2004), nesses momentos de crise econômica mundial, o país experimentou períodos de crescimento econômico, principalmente com o desenvolvimento de sua indústria, deslocando-se assim de sua posição eminentemente agrário-exportadora.

Ainda segundo o autor, as experiências de desenvolvimento econômico experimentadas pelo Brasil, em conjunto com alguns outros países da periferia do 


\section{Althaห̧ão}

ISSN: 1984-6444 | http://dx.doi.org/10.5902/1984644442037

capitalismo mundial, representaram alguns avanços em sistemas de proteção social, que, no entanto, não retiraram o país de sua condição de subdesenvolvimento em relação a níveis de pobreza, políticas sociais e desigualdade econômica. O sistema de proteção social, financiado no país segundo um modelo que desconta do valor do trabalho os recursos para as políticas públicas de saúde, educação, previdência e assistência (POCHMANN, 2004, p. 10), abrange historicamente apenas o um terço formal da mão de obra trabalhadora disponível, de modo que não se constituiu no país, em nenhum momento histórico ${ }^{2}$, uma sociedade assalariada, um dos fundamentos de um Estado de Bem Estar Social (POCHMANN, 2004, p. 15).

Os avanços que puderam acontecer no sistema de proteção social do Estado brasileiro responderam a lutas políticas da sociedade organizada, com as decorrentes alternâncias entre períodos de democracia política e possíveis avanços da luta popular, e de regimes ditatoriais para a manutenção de privilégios das elites, sob a injunção de forças econômicas internas e externas, principalmente norteamericanas, no século $X X$, a que se orquestraram outras, entre os momentos finais do século passado e as décadas iniciais do século XXI, com a aceleração dos processos de globalização financeira. Nessa posição economicamente periférica e heteronômica, a formação do Estado brasileiro realizou-se de modo que, historicamente, a dois terços da sociedade se destinam relações de trabalho não formais. Esse excedente de mão de obra em parte ainda tributário da não inclusão social dos ex-escravizados, contribui para o rebaixamento do valor de remuneração do trabalho formal (POCHMANN, 2004, p. 13), com as consequências sociais e políticas resultantes desse processo de exploração econômica.

Se, no período de 1930 a 1980, houve processos de desenvolvimento econômico que possibilitaram a implementação, ainda que parcial, de políticas públicas de proteção social, após a crise do capital da década de 1970, o país não mais havia encontrado possibilidades de promover políticas de expansão do Estado em direção ao bem estar social, enquanto concomitantemente fortalecia-se sua posição dependente do capital estrangeiro (OMETTO; FURTUOSO; SILVA, 1995; CARDOSO Jr., 2001; PAULANI, 2012). Uma vez consolidada a abertura política e a promulgação da Constituição Federal de 1988, que garantiriam acesso a políticas 


\section{N Wsm elithabá}

ISSN: 1984-6444 | http://dx.doi.org/10.5902/1984644442037

fragilizados com 0 processo de desindustrialização a partir dos anos 80 (BIELSHCHOWSKY, 2012).

As políticas de oferta mais ampla de educação, de garantia do respeito aos direitos humanos, e de manutenção dos direitos trabalhistas, no entanto, suscitaram nova reação das elites financeiras, econômicas e políticas, já desde o final do primeiro governo Dilma Roussef, em 2013. Promoveu-se então nova ruptura no processo democrático no país, em 2016, com o processo de impeachment coordenado por forças empresariais (incluída a mídia hegemônica), grupos políticos e setores do sistema judiciário. O grupo que, com a ruptura democrática, assomou ao poder, implementou mais uma parte das reformas do Estado - econômicas, trabalhistas e educacionais, principalmente - , as denominadas $2^{a}$ geração de reformas, que não se tinha obtido êxito em implementar ainda nos anos 1990 (PINHEIRO; GIAMBIAGI; MOREIRA, 2001).

Assim, às concorrências entre modelos liberais, patrimonialistas e progressistas, historicamente constitutivas da ordenação social, política e ideológica no país, desde após a independência em relação a Portugal (FERNANDES, 1976), e aos movimentos desenvolvimentistas e populistas estabelecidos após os anos 1930 (c.f.: BASTOS, 2003; PAULANI, 2012), acrescentam-se, nas décadas finais do século XX e também no início do século XXI, os efeitos de políticas neoliberais, com o objetivo de reposicionar o Estado em favor dos interesses financeiros, orientados pelas regras estabelecidas pelos países centrais do capitalismo para os países periféricos. Nesse processo, observa-se que a posição heteronômica do país na ordem econômica mundial permanece sendo reproduzida (DATHEIN, 2003).

\section{A reestruturação do Estado brasileiro em bases neoliberais}

Para a observação dos processos de formação da sociedade brasileira (e de seu Estado, em momentos históricos específicos) é preciso considerar, como mencionado, sua posição heteronômica nas relações geopolíticas, e, portanto, observar as diferenças nas formações ideológicas e nas produções discursivas 


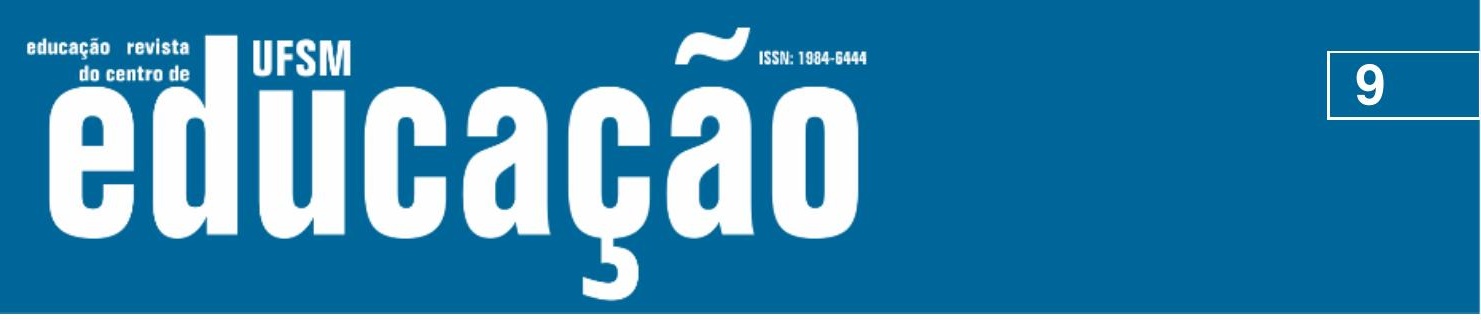

ISSN: 1984-6444 | http://dx.doi.org/10.5902/1984644442037

próprias aos países capitalistas centrais e as que se desenvolvem em países não centrais, como o Brasil.

Foucault (2008) considera a formação dos Estados como um processo em contínua construção, como a produção ininterrupta de um vir a ser estabelecido segundo uma ordem necessária, como um dever ser. Segundo Foucault (2008, p. 06):

O Estado é ao mesmo tempo o que existe e o que ainda não existe suficientemente. E a razão de Estado é precisamente uma prática, ou antes, uma racionalização de uma prática que vai se situar entre um Estado apresentado como dado e um Estado apresentado como a construir e a edificar. A arte de governar deve então estabelecer suas regras e racionalizar suas maneiras de fazer propondo-se como objetivo, de certo modo, fazer o dever-ser do Estado tornar-se ser. O dever-fazer do governo deve se identificar com o dever-ser do Estado. O Estado tal como é dado a ratio governamental - é o que possibilitará, de maneira refletida, ponderada, calculada, fazê-lo passar ao seu máximo de ser. O que é governar? Governar segundo o princípio da razão de Estado é fazer que o Estado possa se tornar sólido e permanente, que possa se tornar rico, que possa se tornar forte diante de tudo o que pode destruí-lo.

A formação dos Estados em países periféricos na ordem capitalista, entretanto, transcorre em processos tensionados por forças internas e externas, nas disputas pela definição das posições a serem ocupadas por um dado país nessa ordem, o que produz efeitos específicos nesse processo de formação.

A formação do Estado brasileiro realiza-se historicamente de modo diverso do proposto por Foucault (2008) em suas considerações referenciadas nos países do capitalismo central (nesse caso, mais especificamente, Inglaterra, Alemanha, Estados Unidos e França). No caso brasileiro, um traço constitutivo do Estado em sua formação é a seletividade, que reordena o princípio apontado por Foucault (2008) quanto à busca pelo seu máximo de ser: Como mostra Fernandes (1976), essa construção, no Brasil, desde sua gênese no pós-independência em relação a Portugal, realiza-se de modo a conciliar elementos mais tradicionais e elementos mais modernizantes, com objetivos de responder diversamente, para controlar, àquilo que possa confrontar os interesses dominantes. Nesse sentido, os preceitos do liberalismo foram implantados de modo seletivo no país, para garantir que 


\section{Althaห̧ão}

ISSN: 1984-6444 | http://dx.doi.org/10.5902/1984644442037

prevalecessem, no processo de inserção do país nos movimentos progressistas que orientavam a ordem internacional de então, os interesses da ordem estamental característica da sociedade brasileira no período.

Estabelecem-se, assim, as bases de uma ordenação social fundada na concorrência de modelos econômicos divergentes ou, mesmo, antagônicos, que responderiam a diferentes projetos de sociedade. Essa ordem em que concorrem modelos econômicos mais tradicionalistas, conservadores, e modelos mais progressistas de sociedade, no estabelecimento de seus processos de formação ideológica, é geralmente apontada como uma das causas do suposto atraso do país em relação a economias consideradas mais desenvolvidas (c.f.: PINHEIRO; GIAMBIAGI; MOREIRA, 2001).

No entanto, no caso brasileiro, com uma sociedade que se caracteriza pela desigualdade extrema e pelas clivagens de todos os tipos que historicamente essa desigualdade violenta institui (econômicas, políticas, culturais, linguísticas), esse suposto atraso parece não se constituir nem como causa nem como resultante de incapacidade produtiva (seja material, seja simbólica) como argumentam os que defendem a necessidade de modernização econômica do país (c.f.: GIAMBIAGI, 2007). Antes que negativa, o atraso parece ter uma função positiva nos processos de construção do Estado e em sua governamentalidade, constituindo um modus operandi que reproduz o funcionamento estabelecido desde sua gênese: trata-se de produzir um Estado que mantenha a ordem de privilégios das classes dominantes, ao mesmo tempo em que instrumentalize a relação assimétrica dessas classes com a ordem econômica internacional, por um lado, e, por outro, governe as massas populacionais pobres que habitam o território, definindo os limites de sua inserção e exclusão social em função do ideário econômico estabelecido em determinada conjuntura.

É preciso considerar assim a eficácia desses delays próprios à produção do Estado brasileiro como um dado instrumental de sua produção e reprodução. O descompasso entre formações ideológicas e discursivas do Estado brasileiro para com as produzidas nas economias centrais, e a concorrência dessas formações as que se constituem nos países capitalistas centrais, e as que se constituem no 


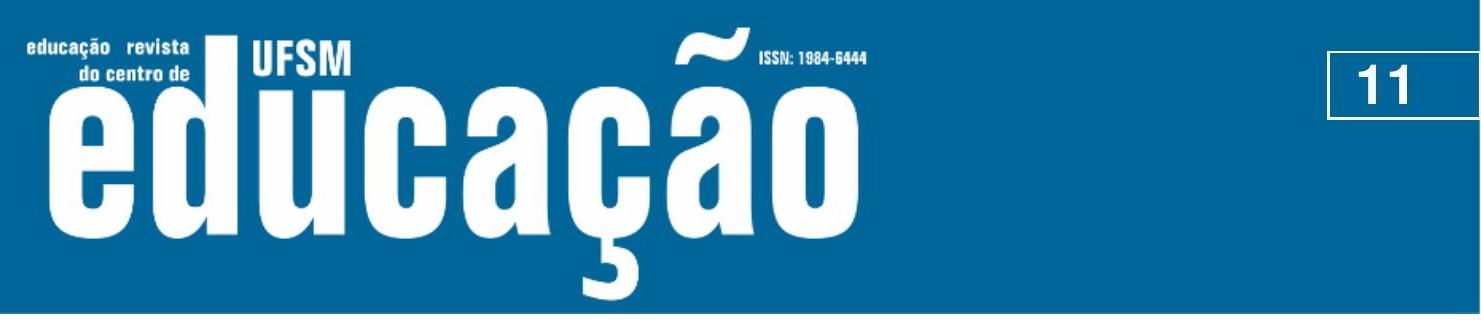

ISSN: 1984-6444 | http://dx.doi.org/10.5902/1984644442037

Brasil - , em sincronia no contexto brasileiro, configura instrumento de conformação do Estado aos interesses econômicos e financeiros nacionais e internacionais, um instrumento fundamental de governança das populações habitantes do território.

Em um sentido, a economia responde aos movimentos produtivos e financeiros do capital, de modo que o Estado não configure entraves aos interesses financeiros internos e externos, tradicionais e emergentes, mas potencialize seus ganhos. Em outro sentido, o Estado funciona para garantir que a governamentalidade das populações no território se faça de modo a regular quem esteja integrado ou não à sociedade, num dado momento, em função das demandas contingenciais por mais ou menos força de trabalho (in)formal e mercado de consumo - o que a Reforma Trabalhista de 2017, ao institucionalizar a flexibilização dos contratos de trabalho, ordenou juridicamente (c.f.: PORTO, 2017).

Os reposicionamentos conjunturais dos limites do Estado definem, assim, quem está autorizado ou não a compor a cidadania e a responder a um dos dois tipos de governamentalidade caracterizados por Foucault (2008): um tipo de governamentalidade de base neoliberal, desenvolvido principalmente após a segunda grande guerra, fundamentado nos processos de construção da sociedade civil em suas relações com o mercado, e centrado no homo oeconomicus, sujeito respeitado em seus interesses e concebido como uma empresa. Nesse contexto, a sociedade civil é um mecanismo de governamentalidade em que se opera a gestão social de modo que o Estado não intervenha nas leis de funcionamento do mercado.

O outro tipo de governamentalidade caracterizado pelo autor é de base policial e corresponderia a um processo que teria sido superado, historicamente, nas economias centrais, pois associado ao período histórico fundado em relações mercantis, com a necessidade colocada por elas de que o Estado garantisse nas relações externas sua sustentabilidade frente ao poder de outros Estados, e, para isso, controlasse internamente sua força produtiva de modo a produzir condições de concorrer no mercado internacional (FOUCAULT, 2008, p. 10).

O que Foucault (2008) propõe como um momento anterior e superado nos processos de governamentalidade estabelecidos historicamente em países centrais da Europa ocidental mantém-se produtivo, porém, nas (ex)colônias do hemisfério sul 


\section{F WEM Eulloahă}

ISSN: 1984-6444 | http://dx.doi.org/10.5902/1984644442037

para a parte mais pobre de suas populações. Nestas (ex)colônias, parte do Estado constitui-se em acordo com o jogo concorrencial fundamentado em preceitos liberais e neoliberais, de modo a responder à ordem econômica internacional hegemônica; outra parte, no entanto, permanece sustentada em relações de dominação e exploração definidas pela impotência nas relações de força estabelecidas com Estados econômica, política e militarmente dominantes, o que, internamente, resulta na ilimitação do poder de polícia do Estado para a manutenção de uma dada ordem social e produtiva fundada na desigualdade e na exploração violenta da parte majoritária da população.

A constituição seletiva e intermitente do Estado brasileiro pode ser compreendida, assim, de dois modos quanto à seletividade e à intermitência estabelecidas pelos grupos produzem e controlam os instrumentos de governamentalidade: amplia-se ou restringe-se o alcance do Estado, em função do escopo e da abrangência das políticas sociais, de modo a favorecer ou a confrontar políticas de bem estar social previstas constitucionalmente; redefine-se quem possa participar da cidadania com o (re)posicionamento dos limites da sociedade civil organizada e politicamente legitimada; redimensiona-se o Estado, segundo princípios econômicos, de modo a circunscrever os que estão autorizados a participar do jogo concorrencial de interesses e os que estão dele excluídos.

Nos países centrais, o Estado ordenado segundo princípios do neoliberalismo é observado como um regulador, de base judiciária, para que as regras do jogo da livre-concorrência estabeleçam-se de modo a garantir a todos os concorrentes equidade na realização de seus interesses. No caso brasileiro (e de outros Estados constituídos em contextos de colonialidade), o Estado (neoliberal) tem como função garantir que sejam realizados os interesses econômicos, de maneira a não apenas preservar a concorrência, mas, nesse caso, também de forma a definir quem pode ou não participar do jogo, mesmo que para ser explorado economicamente.

A seletividade constitutiva do Estado brasileiro, desde seu processo de formação pós-independência de Portugal, parece manter-se produtiva, portanto, como evidenciam os dados relativos à distribuição da riqueza no país, à inclusão ou exclusão dos sujeitos nos limites recobertos pelo Estado, e à inserção ou não dos 


\section{Authaดูã}

ISSN: 1984-6444 | http://dx.doi.org/10.5902/1984644442037

trabalhadores no mercado formal de trabalho (POCHMAN, 2004; ANTUNES; POCHMAN, 2007; GÓMEZ VILLAR, 2010; BENTES, 2012; CARVALHO, 2014; LINHARES, 2015). Nesse sentido, a seletividade do Estado brasileiro parece caracterizar-se por ser instrumental e regular: contingentes populacionais são inseridos ou excluídos dos limites sociais abarcados pelo Estado de acordo com os interesses dos grupos que dele apropriam-se em determinados momentos históricos. ${ }^{3}$

Aos princípios econômicos de caráter neoliberal implantados no país, nos anos finais do século $X X$ e iniciais do século $X X I$, que têm definido os modos de governança do Estado brasileiro mesmo nos momentos em que ideologias de caráter social orientaram os projetos de governo, é preciso somar os processos de financeirização e rentismo que têm ordenado políticas econômicas nos últimos decênios do século XX e iniciais do XXI. Aos dois tipos de governamentalidade caracterizados por Foucault (2008), portanto, é preciso somar mais um, que se constitui com o processo de financeirização do capital. Esse processo possibilita que os detentores do capital movimentem seus investimentos do capital produtivo ao capital financeiro de acordo com as condições econômicas conjunturais estarem mais ou menos em consonância com seus interesses. A flexibilidade que os investidores têm para a proteção de seus investimentos resulta em enfraquecimento das relações sociais de produção, levando à intermitência da produção e, com ela, à precarização do trabalho (c.f.: PAULANI, 2009, p. 28).

Constitui-se, assim, um processo de formação do Estado caracterizado pela complexidade resultante da concorrência de pelo menos três concepções: a que se encontra promulgada na Constituição Federal de 1988, orientada para o desenvolvimento de políticas de bem estar social (ou, pelo menos, de atenção estatal à produção da cidadania); as de caráter neoliberal, implantadas no país nos governos Fernando Henrique Cardoso (1994-2002), atenuadas nos governos petistas (2003-2016), e fortalecidas no governo Temer (2016-2018); as de caráter financeiro-rentistas, com o fortalecimento dos movimentos de liberalização e desregulamentação dos processos econômicos, a financeirização dos mercados em 


\title{
usm Autthabat

ISSN: 1984-6444 | http://dx.doi.org/10.5902/1984644442037

concorrência com o capital produtivo, e o consequente deslocamento das relações de força entre classes sociais que se constituem na ordem capitalista produtiva. e.

Desse modo, no momento mesmo em que, no processo de luta pela redemocratização, é projetado um Estado voltado para o atendimento social e para os direitos do cidadão e do trabalhador, segundo princípios que fundamentam a elaboração da Constituição Federal de 1988, são implantadas no país políticas de caráter neoliberal, enquanto se opera, na macroeconomia mundial, e para a parcela da sociedade brasileira alinhada a essa macroeconomia, movimento que garante instrumentos para que o capital possa desvencilhar-se das injunções que o Estado ou a sociedade possam ter sobre os modos de produção e acumulação:

\begin{abstract}
A ideia básica é que os detentores das ações e de volumes importantes de títulos de dívida privados e públicos são efetivamente proprietários situados numa posição de exterioridade à produção, e não "credores" como normalmente se caracteriza, o que leva à distinção entre finanças intermediadas, que caracterizariam o regime de acumulação anterior, e finanças diretas, que prevalecem no regime atual. Para Chesnais ${ }^{4}$, o termo "credor" remete a "empréstimo" e a um papel das finanças que é em última instância o de direcionar as poupanças para quem deseja investir. Mas a finança atual não é, como essa, movida pelas necessidades da produção e da criação de riqueza nova. Sua instituição central é o mercado secundário de títulos, o qual só negocia ativos já emitidos. (PAULANI, 2009, p. 27).
\end{abstract}

O rentismo e a financeirização produzem, então, um espaço de "exterioridade à produção no seio da própria produção" (PAULANI, 2009, p. 27), deslocando a luta de classes em favor dos que têm o poder de reposicionar seu capital dos modos de produção para o investimento em ativos financeiros, e vice-versa, de acordo com suas conveniências e seus interesses. O jogo torna-se, portanto, ainda mais desigual dada a possibilidade estratégica de retirada dos investimentos, pelos detentores do capital, da força produtiva: 


\section{Tism \\ 7 ISSN: 1984-6444 \\ Filloahao}

ISSN: 1984-6444 | http://dx.doi.org/10.5902/1984644442037

A prevalência da valorização financeira é qualitativa mais do que quantitativa. $O$ fato de sua exterioridade em relação à produção ter se alojado no seio mesmo da esfera produtiva é que explica um sem-número de mudanças aí ocorridas, seja na relação de trabalho (crescimento do trabalho precarizado e informal, do número de trabalhadores temporários, autônomos e em tempo parcial etc.), seja na forma de gestão do processo de trabalho (trabalhadores flexíveis, toyotismo), seja ainda na organização do processo produtivo como tal (generalização do just in time, costumeirização da produção, deslocalizações produtivas). (PAULANI, 2009, p. 28).

Observa-se, assim, a colocação do Estado como função do poder econômicofinanceiro de modo distinto de como historicamente realizado: na ordem referenciada no capital produtivo, as mudanças nos modos de produção capitalista posicionam o Estado como financiador das condições de produção, com investimentos em infraestrutura e em formação de força de trabalho qualificada. $\mathrm{Na}$ ordem fundada na financeirização, o Estado constitui-se como mais um agente financeiro no sistema, emissor de títulos de dívida pública que transfiram ao mercado financeiro o que se arrecada com as políticas fiscais, o que concorre com sua função de financiador de condições de produção para o capital produtivo. Nessa ordem, o Estado atua no sentido de atualizar, modernizar - na perspectiva dos interessados - suas leis com o objetivo de torná-las coerentes com os modos de exploração do capital financeiro, o que implica fazer com que as relações sociais, principalmente as de trabalho e de assistência/previdência, tornem-se flexíveis, flutuantes, como são flexíveis e flutuantes os fluxos de capital entre o rentismo e a produção.

\section{Os modelos político-econômicos e a distribuição de bens linguísticos em contexto brasileiro}

Nos documentos oficiais de parametrização das políticas públicas para a Educação, produzidos desde a década de 1970 no Brasil (momento da ampliação do acesso à escolarização básica pública no país), observa-se a alternância em concepções de sujeito, de língua e de ensino/aprendizagem, em função dos projetos de governo desenvolvidos no período. Esses projetos realizaram-se de modo a 


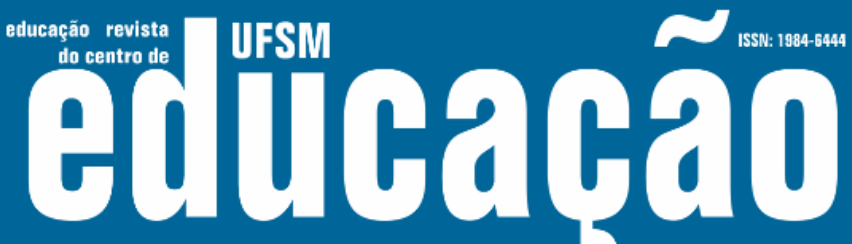

ISSN: 1984-6444 | http://dx.doi.org/10.5902/1984644442037

reconfigurar a abrangência planejada para o Estado em relação à parcela da sociedade a ser pressuposta como participante da cidadania ou não, e a condição prevista para a vida dos sujeitos em sociedade: se em concorrência ou em solidariedade.

Observa-se, assim, um tensionamento entre concepções de aprendizagem de caráter mais individualista ou mais social, fazendo prevalecer ora uma ora outra das posições ideológicas em concorrência, mantendo-se, porém, o discurso de base neoliberal em posição de dominância, nesse período histórico, com períodos de fortalecimento de discursos de caráter sócio-histórico (c.f.: Pietri, 2018; 2019).

Em um dos projetos em concorrência, para que o sujeito participe da cidadania é necessário que ele aproprie-se dos recursos linguísticos que the possibilitarão atuar nos contextos sociais de que pretenda participar. O estabelecimento de condições prévias para a participação social é observado nos Guias Curriculares (São Paulo, 1975), em resposta às finalidades que o regime militar impôs à educação como função de projeto econômico desenvolvimentista (SOARES, 2002), e nos Parâmetros Curriculares Nacionais de Língua Portuguesa (BRASIL, 1998), que também respondeu a projeto de desenvolvimento econômico.

A não pressuposição da cidadania pelo Estado é combatida em documentos de referência curricular publicados em momentos posteriores a cada um dos referidos anteriormente, em contextos de fortalecimento das políticas sociais e assistenciais/previdenciárias. Nos discursos de que são representativos os documentos referentes às Propostas Curriculares (SÃO PAULO, 1988) e às Orientações Curriculares para o Ensino Médio (BRASIL, 2006), por exemplo, , define-se a oposição ao estabelecimento de pré-requisitos estatais à cidadania, defendendo-se o pressuposto de que o sujeito é cidadão a priori, independentemente de ser ou não um falante/escritor da variedade linguística legitimada oficialmente.

Uma diferença fundamental entre os discursos de base social e os de base concorrencial está, portanto, em que, naqueles, postula-se a cidadania dos sujeitos como anterior à apropriação que venham a fazer da língua estabelecida nas políticas oficiais de distribuição linguística, enquanto na vertente ideológica concorrente 


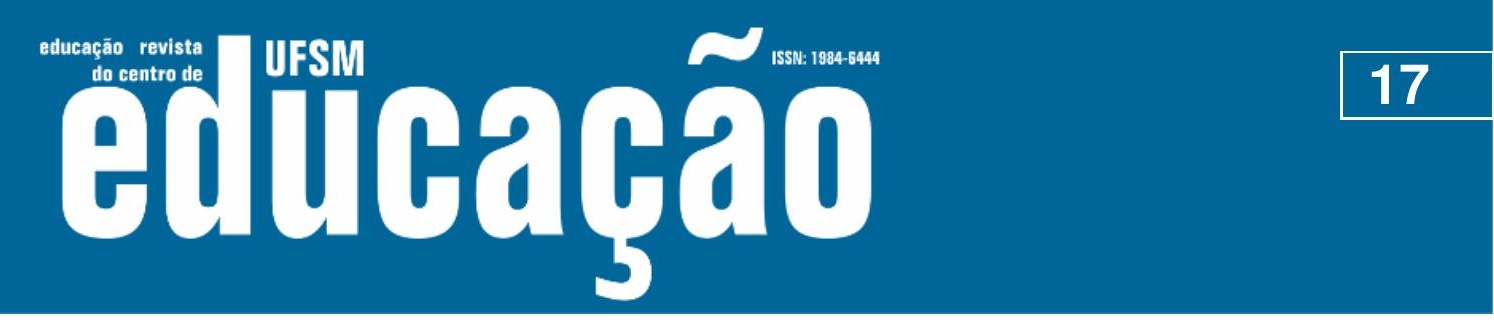

ISSN: 1984-6444 | http://dx.doi.org/10.5902/1984644442037

pressupõe-se uma cidadania condicionada. A polêmica que se estabelece entre esses discursos (MAINGUENEAU, 1997; 2005), no que se refere aos processos de distribuição de bens linguísticos, encontra-se explicitada em sua materialidade nos documentos do Pacto Nacional para a Alfabetização na Idade Certa (PNAIC), programa nacional de distribuição de escrita:

\begin{abstract}
É com base no reconhecimento dessas semelhanças entre o que está presente em propostas curriculares elaboradas em diferentes partes do país, que se pode afirmar que alguns conhecimentos e algumas capacidades cognitivas possam fazer parte dos acordos firmados nas escolas públicas que tenham como finalidade a construção de situações favoráveis de aprendizagem, em uma perspectiva inclusiva, isto é, em uma perspectiva de garantia de aprendizagem para todos. A busca por um currículo inclusivo rompe com os valores relativos à competitividade, ao individualismo, à busca de vantagens individuais. Os princípios de um currículo inclusivo incluem a definição de alguns conhecimentos a serem apropriados por todos os estudantes, respeitando-se as singularidades, diferenças individuais e de grupos sociais. (BRASIL, 2012, pág. 7-8).
\end{abstract}

Nesse discurso, recupera-se a concepção de que a linguagem é constitutiva da subjetividade - enunciado que refere as propostas curriculares de base sociointeracionista para o ensino de língua portuguesa produzidas por diferentes estados da federação na década de 80 (c.f.: GERALDI, SILVA \& FIAD, 1996) —, e, com ela, o pressuposto do direito de todos os sujeitos ao aprendizado, concebendose a língua como um instrumento de simbolização e de ação sobre a realidade, o que se contraporia aos preceitos de base individualista e concorrencial estabelecidos mais explicitamente como política de Estado desde a década de 1990, mas já presentes nos projetos oficiais de currículo na década de 1970.

Os discursos em concorrência que fundamentam as concepções e propostas para a educação linguística nas décadas finais do século $X X$ e iniciais do século $X X I$ respondem, assim, a projetos divergentes de construção do Estado: um projeto em que se desconsideram as desigualdades estruturais que conformam historicamente a sociedade brasileira, e em que se naturaliza a posição heteronômica do país na ordem econômica mundial, submetendo-o a interesses do capitalismo central; e um projeto de Estado que se contrapõe às clivagens econômicas constitutivas da organização social no país, com as violências que delas decorrem, observando-se 


\section{Lism Eutlathat

ISSN: 1984-6444 | http://dx.doi.org/10.5902/1984644442037

Após a deposição do governo Dilma, pela orquestração das forças econômicas, midiáticas e judiciárias, no ano de 2016, as reformas realizadas submeteram mais fortemente o Estado aos interesses do capital. A partir desse momento de ruptura institucional para a instauração da chamada $2^{\underline{a}}$ geração de reformas no Estado brasileiro, principalmente a trabalhista, o princípio concorrencial como forma de governamentalidade passou a ser imposto também à parcela da população historicamente excluída social e economicamente.

No contexto então inaugurado no país, as concepções em que se fundamentavam as propostas de educação linguística estabelecidas em períodos anteriores - em que se definia um conjunto de conhecimentos linguísticos a serem ensinados, fundamentados em bases teórico-metodológicas específicas - são suplantadas pelo estabelecimento de um rol de competências e habilidades, conceitos que, então, são apresentados sem que seja explicitado um referencial teórico que os defina (diferentemente do que se operacionalizou nos Parâmetros Curriculares Nacionais na década de 1990). O desenvolvimento de competências e habilidades pelos estudantes da escola básica seria favorecido ou limitado em função das condições mais ou menos adversas do contexto socioeconômico em que a escolarização venha a realizar-se., Todavia, as desigualdades nas condições de oferta de escolarização, decorrentes de desigualdades sociais e econômicas, não são consideradas quando é proposta uma base nacional comum curricular em que as diferenças nas condições de ensino e aprendizagem apresentam-se resumidas a questões de caráter didático-pedagógico e cultural:

\footnotetext{
Além disso, BNCC e currículos têm papéis complementares para assegurar as aprendizagens essenciais definidas para cada etapa da Educação Básica, uma vez que tais aprendizagens só se materializam mediante o conjunto de decisões que caracterizam o currículo em ação. São essas decisões que vão adequar as proposições da BNCC à realidade local, considerando a autonomia dos sistemas ou das redes de ensino e das instituições escolares, como também o contexto e as características dos alunos. Essas decisões, que resultam de um processo de envolvimento e participação das famílias e da comunidade, referem-se, entre outras ações, a:
} 


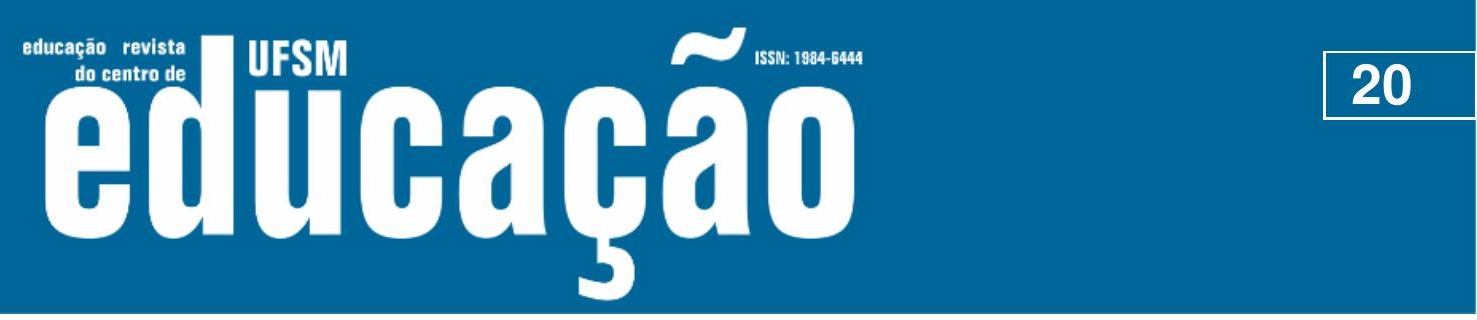

ISSN: 1984-6444 | http://dx.doi.org/10.5902/1984644442037

- contextualizar os conteúdos dos componentes curriculares, identificando estratégias para apresentá-los, representá-los, exemplificá-los, conectá-los e torná-los significativos, com base na realidade do lugar e do tempo nos quais as aprendizagens estão situadas;

- decidir sobre formas de organização interdisciplinar dos componentes curriculares e fortalecer a competência pedagógica das equipes escolares para adotar estratégias mais dinâmicas, interativas e colaborativas em relação à gestão do ensino e da aprendizagem;

- selecionar e aplicar metodologias e estratégias didático-pedagógicas diversificadas, recorrendo a ritmos diferenciados e a conteúdos complementares, se necessário, para trabalhar com as necessidades de diferentes grupos de alunos, suas famílias e cultura de origem, suas comunidades, seus grupos de socialização etc.;

- conceber e pôr em prática situações e procedimentos para motivar e engajar os alunos nas aprendizagens;

- construir e aplicar procedimentos de avaliação formativa de processo ou de resultado que levem em conta os contextos e as condições de aprendizagem, tomando tais registros como referência para melhorar o desempenho da escola, dos professores e dos alunos;

- selecionar, produzir, aplicar e avaliar recursos didáticos e tecnológicos para apoiar o processo de ensinar e aprender;

- criar e disponibilizar materiais de orientação para os professores, bem como manter processos permanentes de formação docente que possibilitem contínuo aperfeiçoamento dos processos de ensino e aprendizagem;

- manter processos contínuos de aprendizagem sobre gestão pedagógica e curricular para os demais educadores, no âmbito das escolas e sistemas de ensino. (BRASIL, 2017, p. 16-17).

Desconsideradas as desigualdades sociais e econômicas em que se desenvolvem os processos de escolarização, a distribuição de bens linguísticos mantém-se dependente do capital econômico e simbólico que os sujeitos possuam ou não, em suas condições sociais, para investir e apropriar-se dos recursos valorizados socialmente, movimento que reitera a ordem desigual que se afirma buscar alterar com a política curricular comum então implementada.

De acordo com o projeto de Estado que se institui após 2016 e que se encontra em desenvolvimento no momento em que se produz este trabalho, mantêm-se e fortalecem-se as condições de produção histórica da desigual distribuição dos bens econômicos e simbólicos, acentuadas com o processo de destruição, em curso, das bases sociais ou assistenciais/previdenciárias e com o reposicionamento das camadas mais pobres da população como partícipes do jogo econômico em bases concorrenciais. Nessas condições, é preciso questionar quais efeitos produzem-se com a implantação de uma política parametrização curricular que estabelece um conjunto de "aprendizagens essenciais" (BRASIL, 2017, p. 07) a 


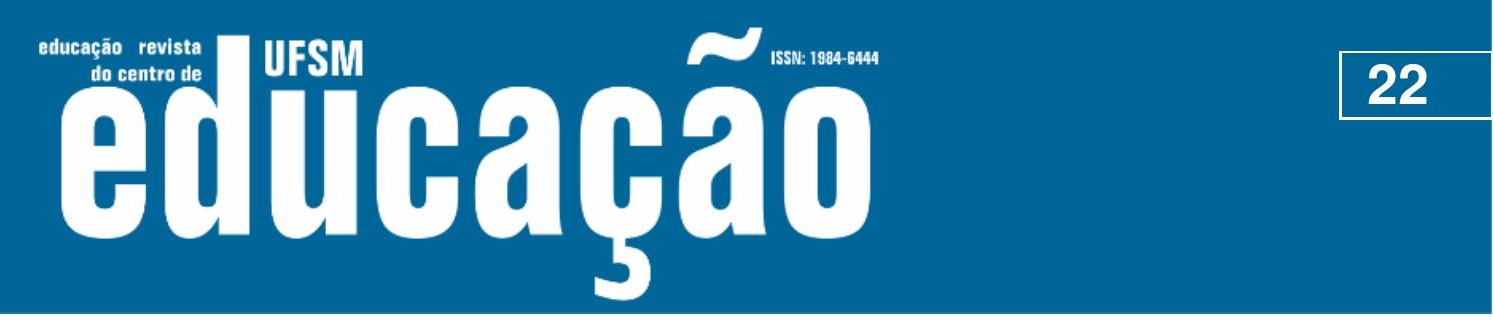

ISSN: 1984-6444 | http://dx.doi.org/10.5902/1984644442037

BRASIL. Secretaria de Educação Fundamental. Parâmetros curriculares nacionais: língua portuguesa. Secretaria de Educação Fundamental. Brasília: MEC/SEF, 1998.

CARDOSO JUNIOR, José Celso. Crise e desregulação do trabalho no Brasil. Revista de Sociologia da USP- Tempo Social, São Paulo, Vol. 13, n. 2, p. 31-59, Nov., 2001.

CARVALHO, Alba Maria Pinho de. A Precarização Estrutural do Trabalho na Civilização do Capital em Crise: O Precariado Como Enigma Contemporâneo. Revista Políticas Públicas, Maranhão, v. 18, p. 225 - 239, julho, 2014.

CHESNAIS, François. O capital portador de juros: acumulação, internacionalização, efeitos econômicos e políticos. In: CHESNAIS, François (org.). Finança mundializada. São Paulo: Boitempo, 2005.

CONTRI, André Luis. Uma avaliação da economia brasileira no Governo Dilma. Indicadores Econômicos - FEE, v. 41, n.4, p. 9-20, 2014.

COUTINHO Luciano; BELLUZZO, Luiz Gonzaga. "Financeirização" da riqueza, inflação de ativos e decisões de gasto em economias abertas. Economia e Sociedade, n. 11, 1998, p. 137-150.

DATHEIN, Ricardo. De Bretton Woods à Globalização Financeira: Evolução, Crise e Perspectivas do Sistema Monetário Internacional. 2003. Disponível em https://www.ufrgs.br/fce/wpcontent/uploads/2017/02/TD05_2003_dathein.pdf. Acesso em: agost. 2017

FERNANDES, Florestan. A revolução burguesa no Brasil. 2ª . Ed. Rio de Janeiro: Zahar, 1976.

FOUCAULT, Michel. Nascimento da biopolítica. São Paulo: Martins Fontes, 2008.

FRANCHI, Carlos. Criatividade e gramática. São Paulo: SE/CENP, 1987.

FREITAS, Luiz Carlos. A avaliação e as reformas dos anos de 1990: novas formas de exclusão, velhas formas de subordinação. Educação \& Sociedade [online]. 2004, vol.25, n.86, p. 131-170.

GERALDI, João Wanderley, SILVA, Lílian L.M. \& FIAD, Raquel S. Linguística, Ensino de Língua Materna e Formação de Professores. In D.E.L.T.A., vol.12, ํㅡ 2, 1996, pp. 307-326.

GIAMBIAGI, Fabio. Brasil, raízes do atraso. Rio de Janeiro: Elsevier, 2007.

GÓMEZ VILLAR, Antonio. El trabajador precario y la construcción del precariado como sujeto del cambio. Astrolabio. Revista internacional de filosofia, n. 11, pp. 209-217, 2010. 


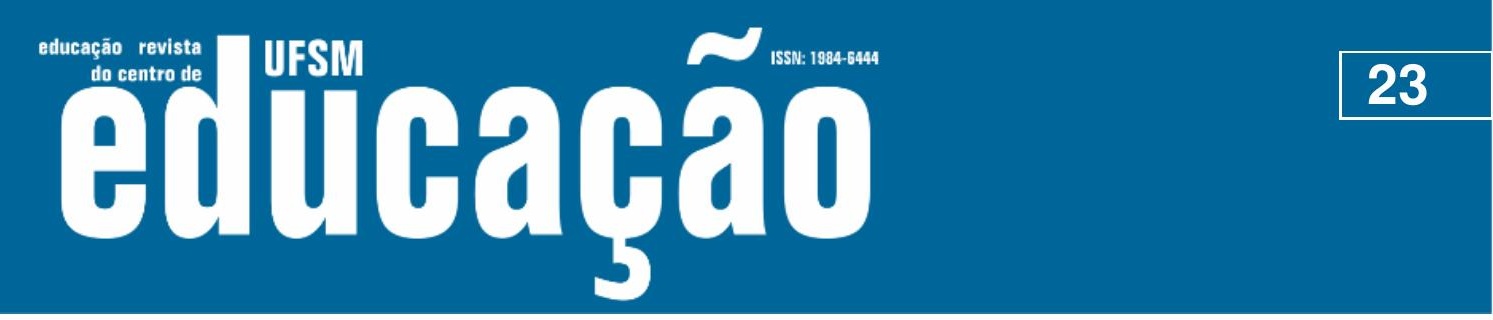

ISSN: 1984-6444 | http://dx.doi.org/10.5902/1984644442037

LINHARES, Maria Isabel S. B. Os favoritos precários. In: BRANDÃO, Israel Rocha; ARAÚJO, José Edvar C. de (orgs.). Educação contextualizada. Fortaleza: Editora Caminhar, 2015.

LUCCHESI, Dante. Língua e sociedade partidas: a polarização sociolinguística no Brasil. São Paulo: Contexto, 2015, 320 p.

MAINGUENEAU, Dominique. Gênese dos discursos. Tradução de Sírio Possenti. Curitiba: Criar, 2005.

MAINGUENEAU, Dominique. Novas Tendências em Análise do Discurso. Tradução de Freda Indursky. Campinas, SP: Editora Pontes, Editora da Unicamp, 1997.

OLIVEIRA, Romualdo Portela de. A transformação da educação em mercadoria no Brasil. Educação e Sociedade, Campinas, v. 30, n. 108, p. 739-760, out., 2009.

OMETTO, Ana Maria H; FURTUOSO, Maria Cristina O; SILVA, Marina V. Economia brasileira na década de 80 e seus reflexos nas condições de vida da população.

Revista de Saúde Pública. São Paulo, vol. 29, n. 5, p. 403-414, Out., 1995.

PAULANI, Leda Maria. A crise do regime de acumulação com dominância da valorização financeira e a situação do Brasil. Estudos Avançados, São Paulo, USP, v. 23, p. 25-39, 2009.

PAULANI, Leda Maria. A inserção da economia brasileira no cenário mundial: uma reflexão sobre a situação atual à luz da história. Boletim de Economia e Política Internacional (IPEA), vol. 3, n.10, Abril, 2012.

PERONI, Vera Maria Vidal; CAETANO, Maria Raquel. O público e o privado na educação Projetos em disputa? Revista Retratos da Escola, Brasília, v. 9, n. 17, p. 337-352, jul./dez. 2015.

PIETRI, Émerson de. A constituição dos discursos sobre ensino de língua portuguesa nas décadas de 1980 e 1990. Trabalhos em Linguística Aplicada, Campinas, v. 57, n. 1, p. 523-550, Apr. 2018.

PIETRI, Émerson de. Dois modos de tratamento da heterogeneidade linguística no Brasil em documentos de referência curricular. Revista E-curriculum (PUCSP), v. 17, p. 1349-1372, 2019.

PINHEIRO, Armando; GIAMBIAGI, Fábio; MOREIRA, Maurício M. O Brasil na década de 90: uma transição bem-sucedida? Rio de Janeiro: BNDES, Departamento Econômico - DEPEC, 2001. 36p. (Textos para discussão, n. 91)

POCHMANN, Márcio. Política social na periferia do capitalismo: a situação recente no Brasil. Ciência e Saúde Coletiva. Rio de Janeiro, v. 12, n. 6, p. 1477-89, 2007. 


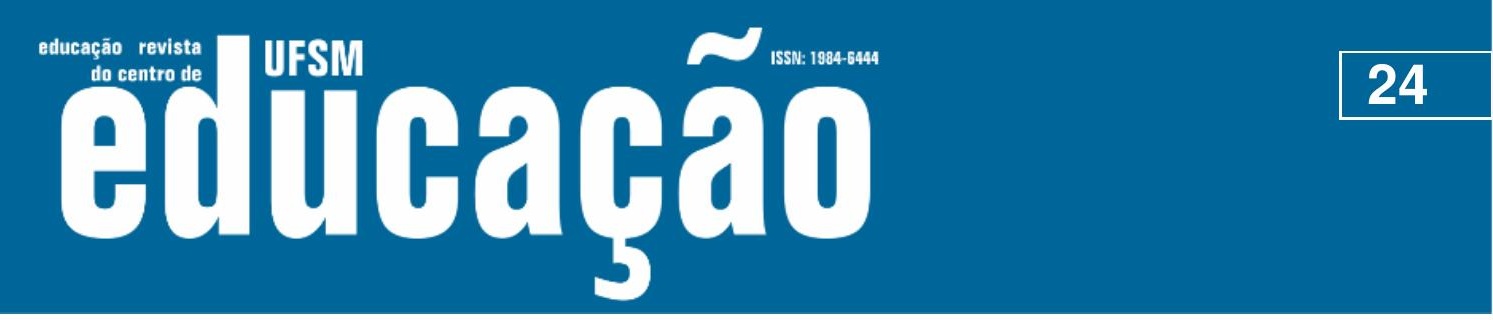

ISSN: 1984-6444 | http://dx.doi.org/10.5902/1984644442037

POCHMANN, Márcio. Proteção social na periferia do capitalismo: considerações sobre o Brasil. São Paulo em Perspectiva, São Paulo, v. 18, n. 2, p. 3-16, Jun., 2004.

PORTO, Lorena Vasconcelos. A terceirização na reforma trabalhista e a violação às normas internacionais de proteção ao trabalho. Revista do Tribunal Regional do Trabalho da 3ª Região. Belo Horizonte, v. 63, n. 96, p. 149-182, jul./dez. 2017.

SADER, Emir. A construção da hegemonia pós-neoliberal. In: SADER, Emir (org.) 10 anos de governos pós-neoliberais no Brasil: Lula e Dilma. São Paulo, SP: Boitempo; Rio de Janeiro: FLACSO Brasil, 2013.

SANTOS, Milton. Por uma outra globalização - do pensamento único à consciência universal. São Paulo: Record, 2000.

SÃO PAULO. Secretaria Estadual de Educação. Proposta Curricular para o Ensino de Língua Portuguesa: 1ํ grau, São Paulo: SE/CENP, 2ª ed, 1988.

SÃO PAULO. Secretaria da Educação. Guias Curriculares para o ensino de 1ำ grau. São Paulo: CERHUPE, 1975.

SOARES, Magda. Português na escola - História de uma disciplina curricular. In: BAGNO, Marcos. (org.). Linguística da norma. São Paulo: Edições Loyola, 2002.

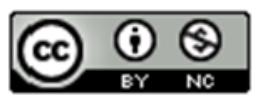

This work is licensed under a Creative Commons Attribution-NonCommercial 4.0 International (CC BY-NC 4.0)

\section{Notas}

\footnotetext{
${ }^{1}$ Como aponta Fernandes (1976), a formação do Estado no Brasil pós-independência se realizou de modo a garantir que se construísse um aparato institucional que inserisse o país na ordem internacional, ao mesmo tempo em que mantivesse os privilégios das elites econômicas e agrárias historicamente detentoras dos poderes políticos no território brasileiro. Assim, princípios liberais orientaram a constituição do Estado brasileiro de modo que garantissem, excentricamente, a manutenção da ordem patrimonialista e estamental historicamente definidora das relações sociais no país.

${ }^{2}$ Nos governos Lula e Dilma (SADER, 2013), na primeira década do século XXI, reposicionou-se parte do Estado para que respondesse a políticas de caráter desenvolvimentista e, com isso, ampliou-se a mão de obra formal no país, ocasionando condições de mais baixos índices de desemprego - pouco abaixo de 5\% no segundo governo Dilma (c.f.: CONTRI, 2014). Ainda que esse processo não tenha ampliado significativamente a proporção de mão de obra formal em relação à informal e parte do Estado continuasse a responder às políticas neoliberais implantadas na década de 90, a reação dos setores conservadores da sociedade e dos grandes grupos financeiros foi brutal, de modo a mobilizar as forças sociais com o uso da mídia hegemônica e das forças
} 


\section{N

ISSN: 1984-6444 | http://dx.doi.org/10.5902/1984644442037

judiciárias e policiais para a retomada do poder político e a recolocação das diretrizes econômicas sob os interesses do capital financeiro/rentista. Com isso e com a reforma trabalhista realizada em 2017 em resposta aos interesses dos grupos que tomaram o poder, o desemprego ampliou-se a taxas de mais de $12 \%$ no período, com o decorrente aumento da informalidade no mercado de trabalho. [Sobre a submissão dos direitos trabalhistas aos interesses econômicos, operada pela Reforma Trabalhista de 2017, c.f.: PORTO (2017)].

${ }^{3} \mathrm{O}$ que é percebido de modo mais evidente em períodos de alternância ideológica: na substituição do trabalho escravizado pela força de trabalho do imigrante europeu; na substituição da mão de obra no campo pelo emprego na indústria, com o consequente processo de urbanização; no fechamento de postos na indústria, com o consequente desemprego e precarização das condições de trabalho, em decorrência da implantação dos princípios neoliberais e do desenvolvimento dos processos de financeirização da economia; nas políticas de pleno emprego e de distribuição de renda mínima, com a inclusão social para o consumo e não para a participação social; com a realização de "reformas" de caráter neoliberal para a retirada de direitos sociais e trabalhistas historicamente conquistados.

${ }^{4}$ Chesnais (2005). 